\title{
Identificação das estratégias de educação alimentar e nutricional desenvolvidas pelos Núcleos de Apoio à Saúde da Família no Distrito Federal como forma de promoção da saúde.
}

\author{
Natascha Façanha Silva Ramos ${ }^{(1)}$ \\ Andréia Araújo Lima Torres ${ }^{(2)}$
}

Resumo: Desde a criação dos Núcleos de Apoio à Saúde da Família (NASFs) em 2008, o profissional nutricionista passou a contar com mais um espaço de atuação para promover a saúde da população junto à atenção básica. Neste campo, a melhor estratégia para se atingir resultados efetivos e sustentáveis na área de práticas alimentares saudáveis é através do pressuposto da educação alimentar e nutricional. Através de questionário estruturado enviado e respondido por endereço eletrônico, 6 nutricionistas que compõem os NASFS do Distrito Federal foram pesquisadas sobre as ações de educação alimentar e nutricional desenvolvidas, durante o período de novembro a dezembro de 2009. Os resultados deste estudo indicam que as nutricionistas estão cientes de sua função educadora dentro da Estratégia de Saúde da Família, porém não conseguem exercê-la de maneira dialógica, conscientizadora e emancipadora. Muitos são os obstáculos, entre os quais: falta de parcerias, dificuldade para trabalho em equipe multiprofissional, estrutura física inadequada, desvio de função e falta de gestão direta.

Palavras-chaves: Nutrição, NASF, Educação Nutricional, Promoção da Saúde, Atenção Básica em Saúde.

\footnotetext{
${ }^{1}$ Nutricionista, estudante de especialização do Núcleo de Estudos em Educação e Promoção da Saúde e mestranda em Nutrição Humana, ambos pela Universidade de Brasília. Endereço: Faculdade de Ciências da Saúde, Conjunto 07 Sala 31, NESPROM, Campus Darcy Ribeiro, Asa Norte - Brasília. CEP: 70.910-000.

$\overline{2}$ Nutricionista, mestre em Nutrição Humana pela UnB, especialista em Educação e Promoção da Saúde e Nutrição Clínica. Professora do Núcleo de Estudos em Educação e Promoção da Saúde da Universidade de Brasília.
} 


\section{Introdução}

A Estratégia de Saúde da Família (ESF) adotada pelo Ministério da Saúde pode ser considerada uma medida de suma importância por se apresentar como eixo norteador e estruturante da atenção básica em saúde desde 1994, após implementação do Programa de Saúde da Família (Senna, 2002). Sua relevância resulta das metas de saúde a serem atingidas, que buscam aumentar o acesso da população aos serviços básicos de saúde - preventivos e promocionais -, assim como a integralidade e multidisciplinaridade inerente de tais ações.

Com vistas à integralidade da ação das equipes da Estratégia de Saúde da Família, em janeiro de 2008 foi publicada a Portaria GM n 154 pelo Ministério da Saúde, cujo conteúdo legal prevê a criação de Núcleos de Apoio à Saúde da Família (NASFs) nos municípios do país, os quais podem ser formados pelos mais variados profissionais de saúde, entre eles o nutricionista.

Segundo a portaria, a criação dos NASFs tem por objetivo "ampliar a abrangência e o escopo das ações da atenção básica, bem como sua resolubilidade, apoiando a inserção da ESF na rede de serviços e o processo de territorialização e regionalização a partir da atenção básica”. Os NASF devem buscar instituir a plena integralidade do cuidado físico e mental aos usuários do Sistema Único de Saúde (SUS) por intermédio da qualificação e complementaridade do trabalho das demais equipes da ESF, realizando ações multiprofissionais e transdisciplinares, e desenvolvendo a responsabilidade compartilhada (Brasil, 2008).

Para compor a equipe NASF, o nutricionista precisa de uma formação voltada para questões sociais, com capacidade de leitura e vivência dos problemas locais existentes em todo o território de abrangência da equipe. Além de ser um especialista em alimentação e nutrição, é também um profissional de saúde coletiva, que deve visar sempre à melhoria da qualidade de vida da população atendida (Boog, 2008).

Este profissional tem um campo vasto de atuação previsto na Matriz de Ações de Alimentação e Nutrição na Atenção Básica de Saúde (Brasil, 2009a), a qual defende que as responsabilidades do nutricionista têm por objetivo central contribuir com o planejamento e a organização das ações de cuidado nutricional local, visando qualificar os serviços e melhorar a sua resolubilidade, atuando de forma efetiva sobre os

determinantes dos agravos e problemas alimentares e nutricionais que acometem a população, especialmente aqueles sob responsabilidade da Atenção Básica de Saúde. 
Sob a óptica do campo da Nutrição, preconiza-se a adoção de ações de promoção de práticas alimentares saudáveis em todas as fases do ciclo da vida e respostas às principais demandas assistenciais quanto aos distúrbios alimentares, deficiências nutricionais e desnutrição, bem como aos planos terapêuticos, especialmente nas doenças e agravos não-transmissíveis (Brasil, 2008). Inquéritos nacionais revelam que aproximadamente 72 milhões de pessoas no país vivem em situação de insegurança alimentar (Brasil, 2006) e que 43,3\% e 13\% da população das capitais brasileiras acima de 18 anos apresentam excesso de peso e obesidade, respectivamente (Brasil, 2009b).

A tendência temporal dessas duas condições nutricionais antagônicas é revelada também por inquéritos nacionais, que indicam que a prevalência de desnutrição, em especial a infantil, diminuiu com o passar dos anos (Brasil, 1977 e Brasil, 2004), de 16,6\% para 4,6\%, respectivamente. Ao contrário, a prevalência de obesidade/sobrepeso encontra-se em franca ascensão, variando de 11,6\% em 2006 para 13\% em 2008 (Brasil, 2009b).

Esses dados condizem exatamente com o processo de transição nutricional pelo qual a população brasileira passa atualmente, sendo caracterizado principalmente pela dupla carga de doenças, ou seja, a coexistência dentro de uma mesma comunidade de agravos nutricionais advindos tanto do excesso e baixa qualidade alimentar, como da falta do acesso ao alimento (Coutinho et al., 2008). Quer dizer, as doenças de cunho nutricional típicas do mundo subdesenvolvido agora compartilham o espaço com as doenças nutricionais do mundo desenvolvido e globalizado.

Dado esse cenário epidemiológico, a inserção de um nutricionista junto às equipes de saúde da família é plausível e promissora. Existem inúmeras ações possíveis ao nutricionista para atuar efetivamente e de forma integral na atenção básica, atentando sempre para o correto manejo conforme o curso da vida. Segundo a Matriz de Ações de Alimentação e Nutrição na Atenção Básica (Brasil, 2009a), esse profissional é responsável, no âmbito individual, familiar e coletivo, por diagnosticar a situação nutricional da comunidade atendida, prevenir doenças e agravos nutricionais, promover hábitos saudáveis de alimentação, tratamento adequado e interdisciplinar e assistência em conjunto com aparelhos sociais.

No âmbito da ESF, a educação em saúde figura como uma prática prevista e atribuída a todos os profissionais que compõem as equipes de saúde da família, inclusive aos do NASF. A educação em saúde constitui um conjunto de saberes e 
práticas orientados para a prevenção de doenças e promoção da saúde, oferecendo subsídios para a adoção de novos hábitos e condutas de saúde por parte da população assistida (Alves, 2005; Coutinho et al., 2008).

A partir da lógica da promoção da saúde, a melhor estratégia para se atingir resultados efetivos e sustentáveis na área de alimentação é através do pressuposto da educação alimentar e nutricional. Essa ferramenta educacional apresenta-se como elemento chave nesse processo. Seria ensinar o conhecimento da Nutrição em caminhos que promovam o desenvolvimento e manutenção de atitudes positivas por meio de comportamento de hábitos alimentares que contribuem para a saúde pessoal, bem-estar e produtividade (Brasil, 2009a). Além disso, todo esse desafio deve ser emoldurado no âmbito da Política Nacional de Alimentação e Nutrição (PNAN), a qual exige um profissional detentor de conhecimentos no campo da ciência da alimentação e da nutrição que integre à sua prática ferramentas da epidemiologia, do planejamento, da educação e de outras disciplinas das ciências sociais e humanas (Assis et al., 2002).

A educação nutricional aqui mencionada é aquela pretendida por Freire (1983), quando coloca que a educação deve ser emancipadora e conscientizadora através de uma relação altamente participativa e dialógica entre educador e educando, contrariando a educação bancária vigente, onde apenas há transmissão vertical de informações e a reprodução quase que inquestionada da estrutura social constituída.

Através dessa educação alimentar e nutricional, o educando tende a desconstruir sua conduta alimentar que é determinada pelo condicionamento e pelo hábito repetido mecanicamente, para reconstruir outra, na qual ele, compreendendo seu próprio corpo e aprendendo a ouvi-lo e observá-lo, passa a ser sujeito ativo (Boog, 1996).

Assim, considerando os argumentos expostos, o presente estudo teve como objetivos principais identificar as ações de educação alimentar e nutricional (EAN) realizadas pelos nutricionistas que compõem os Núcleos de Apoio à Saúde da Família (NASF) em processo de implantação no Distrito Federal (DF), analisando se estão condizentes com aquilo que é proposto pela Matriz de Ações de Alimentação e Nutrição na Atenção Básica de Saúde (Brasil, 2009a) e pela sua portaria de implantação (Brasil, 2008). 


\section{Metodologia}

O presente estudo é uma pesquisa predominantemente qualitativa, dada sua intenção em compreender os significados atribuídos às ações educativas, ferramentas imprescindíveis para promover a saúde da população assistida pelos NASFs e capacitar os profissionais das demais equipes de saúde da família.

A pesquisa foi realizada junto aos profissionais nutricionistas que compõem os NASF do DF, os quais atualmente encontram-se em processo de implantação. Nos meses de novembro a dezembro de 2009 foi enviado aos nove nutricionistas um questionário estruturado, objetivo, composto por quatro blocos principais (identificação, caracterização profissional, ações de educação alimentar e nutricional e condições de trabalho) através de endereço eletrônico, juntamente ao termo de consentimento livre e esclarecido (TCLE).

O arcabouço teórico do estudo tem suas bases na Teoria das Representações Sociais (TRS), proposta pela primeira vez em 1961 por S. Moscovici. A TRS é uma forma de conhecimento socialmente elaborado e compartilhado, que contribui para a construção de uma realidade comum a um conjunto social (Jodelet, 2002) e cujo objetivo prático é explicar os fenômenos do homem a partir de uma perspectiva coletiva, sem perder de vista a individualidade (Sá, 1998).

A metodologia utilizada para análise dos dados obtidos baseou-se na proposta do método do Discurso do Sujeito Coletivo (Lefèvre \& Lefèvre, 2003), associado ao software Qualiquantisoft ${ }^{\circledR}$ (versão teste). A partir desse método, é possível elencar e articular uma série de operações sobre os depoimentos coletados por meio de questões abertas. Tais operações redundam, ao final do processo, em depoimentos coletivos confeccionados com extratos de diferentes depoimentos individuais: cada um desses depoimentos coletivos veiculam uma determinada e distinta opinião ou posicionamento (Lefèvre \& Lefèvre, 2006).

O presente estudo atende às disposições da Resolução n¹96/96 CNS/MS, referentes a pesquisas envolvendo seres humanos, tendo sido submetida e aprovada pelo Comitê de Ética em Pesquisa da Fundação de ensino e Pesquisa em Ciências da Saúde (FEPECS) do Distrito Federal, sob o parecer n.318/2009 de 10 de novembro do mesmo ano. Todos os voluntários foram esclarecidos quanto aos objetivos da pesquisa e assinaram o TCLE. 


\section{Resultados e Discussão}

O tempo médio de resposta aos questionários foi de aproximadamente 17 dias após a aprovação do projeto pelo Comitê de Ética em Pesquisa da FEPECS e envio para os respectivos endereços eletrônicos. Durante este período também foram recolhidos os TCLE devidamente assinados.

\section{As nutricionistas do NASF}

Aproximadamente 1/3 da amostra trabalha há 10 meses no NASF, ao passo que o restante delas ocupa o cargo, em média, há 7,5 meses. Esse resultado indica que a implantação dessa nova ação dentro da Estratégia de Saúde da Família teve início no Distrito Federal em janeiro de 2009. Todas as nutricionistas do NASF ocupam o cargo devido à aprovação em concurso público, e cumprem jornada de trabalho de 40 horas semanais. À exceção de uma delas, que por motivo de gestação obteve horário especial de trabalho, cumprindo 24 horas por semana.

Mesmo após um ano do início da implantação do NASF no Distrito Federal, as equipes (mínimas) ainda encontram-se incompletas, contando atualmente somente com um profissional nutricionista em todas elas, e terapeuta ocupacional ou fisioterapeuta. Até certo ponto este é um dado intrigante, uma vez que o recurso para implementação e manutenção desses núcleos não provém do orçamento distrital para saúde, e sim de uma verba específica destinada direta (de Fundo Nacional de Saúde a Fundo Distrital de Saúde) e exclusivamente para eles, conforme dispõe a Portaria $n^{\circ} 154 / 08$. A depender do tipo de NASF (1: três profissionais ou 2: cinco profissionais) que será definitivamente efetivado no DF, o valor de implantação a ser repassado em parcela única é de seis ou vinte mil reais, acrescido de parcelas mensais de custeio que também podem ser de seis ou vinte mil reais, respectivamente (Brasil, 2008).

Por uma lógica natural e capitalista, era de se esperar um número maior de equipes e profissionais no NASF. É possível que o repasse desse montante não seja adequado ao tipo e número de profissionais e atividades a serem desenvolvidas. Neste caso, é possível a complementação com verbas do próprio DF para aumento da abrangência e efetividade das ações programáticas dos NASFs. 
Considerando, ainda, a atual conjectura política de escândalos de corrupção por parte dos três Poderes distritais e ameaça de intervenção federal na administração do DF por parte do Superior Tribunal Federal (Campos, 2010), é provável que não somente a ESF, mas também vários outros programas e políticas mantenham-se estagnados até o desfecho dessa situação.

Dos nove profissionais nutricionistas inicialmente contatados para participarem da pesquisa, somente seis (66,67\%) responderam aos questionários enviados, e todas são do sexo feminino, com uma média etária de 29,3 anos (desvio-padrão de 2,73 anos), dentro de uma variação entre 26 e 33 anos. Apesar de terem sido re-convidadas a participar da pesquisa, as três nutricionistas restantes sequer manifestaram opinião.

A maioria das profissionais (83,33\%) trabalham junto às unidades básicas de saúde (UBS) localizadas nas regiões mais à oeste do DF: 3 em Samambaia, 1 em Brazlândia e 1 na Cidade Estrutural. Apenas uma delas trabalha no Núcleo de Arapoanga, em Planaltina, localizado à nordeste do DF. A população que atualmente habita essas regiões administrativas corresponde a aproximadamente 625 mil pessoas, ou seja, 24\% da população estimada do DF (Brasília, 2005).

Porém, não está totalmente coberta. De acordo com dados fornecidos extraoficialmente (via telefone) pela Gerência de Nutrição da Secretaria de Saúde do DF, a atual cobertura desses NASFs é praticamente nula, pois embora haja vontade política em implantá-los definitivamente no DF, não foram oferecidas as devidas orientações e capacitações para se delinear e delimitar o que seria a prática de atenção em saúde do NASF. Infelizmente, as equipes do NASF que deveriam estar atuando em conjunto com as equipes de saúde da família e agentes comunitários de saúde estão hoje reclusas às mesmas atividades exercidas pelos profissionais dos centros de saúde.

\section{A Prática Educativa}

Para as nutricionistas, a importância do trabalho realizado diariamente junto à população adscrita ao NASF encontra-se discriminado no gráfico 1 a seguir. Das 15 respostas obtidas para essa questão, prevenção de doenças e agravos (40\%) e promoção da saúde (26,66\%) constituíram-se como as mais prevalentes. Conforme Discurso do 
Sujeito Coletivo (DSC 1) abaixo, também é possível constatar outros campos em que as ações de educação alimentar e nutricional (EAN) são importantes para elas:

A alimentação e Nutrição é um braço fundamental da promoção da saúde. Além de servir como forma de prevenção de muitas doenças evitáveis, reduz o agravamento de doenças crônicas já instaladas, diminui o risco de adoecimento e melhora a qualidade de vida. A educação nutricional é de fundamental importância porque ensina o indivíduo a escolher melhor os alimentos e a maneira correta de prepará-los e de como combiná-los. As pessoas que passaram pelo processo se tornam multiplicadoras da informação dentro da comunidade, reduzindo o fluxo para os serviços terciários do sistema de saúde. Porém, não se aprende na faculdade a promoção da alimentação saudável para pessoas que não têm o que comer, em comunidades extremamente carentes, onde existem sérios problemas de violência, drogas, saneamento...

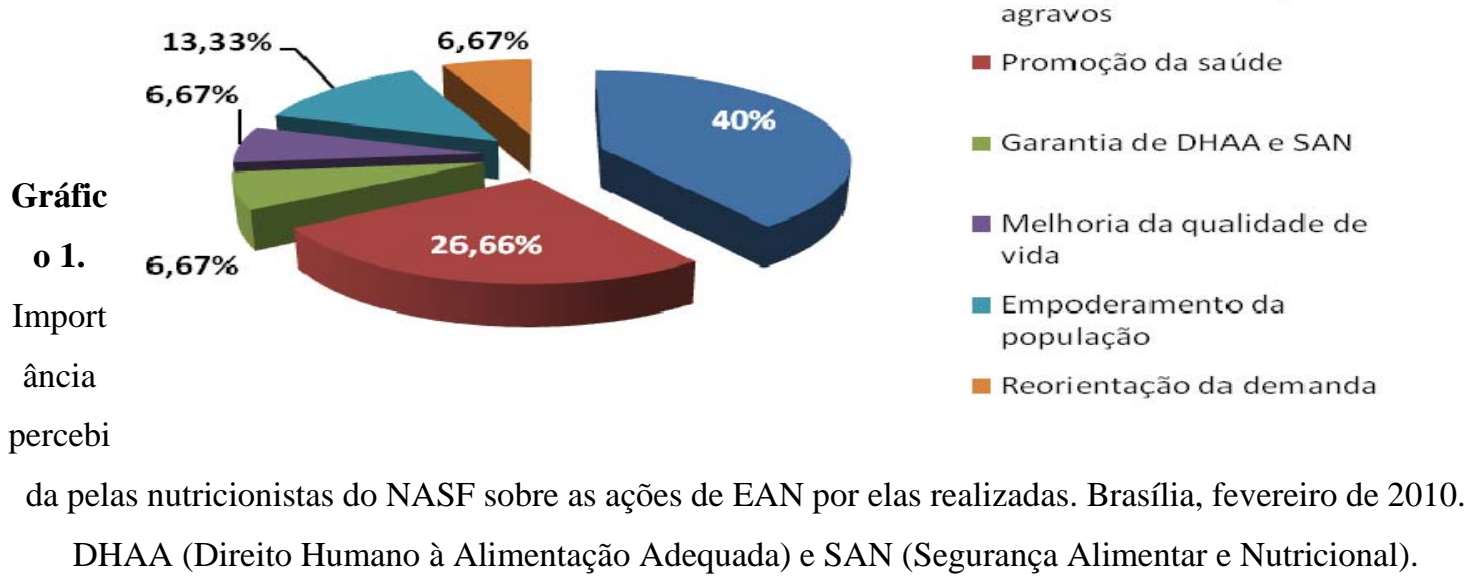

A atuação em Nutrição, entendida como componente do trabalho interdisciplinar, é oportuna sob quaisquer formas de intervenção a todo programa cuja finalidade seja elevar a qualidade de vida da população a partir do princípio da integralidade (Assis et al., 2002).

O nutricionista do NASF é responsável pela promoção de práticas alimentares saudáveis, que é um componente importante da promoção da saúde em todas as fases do ciclo da vida e abrange os problemas vinculados à desnutrição, incluindo as carências específicas, a obesidade e os demais distúrbios nutricionais e sua relação com as 
doenças e agravos não-transmissíveis. Este profissional deve, entre outras atividades, promover a articulação intersetorial, capacitar a equipes da ESF e participar de ações vinculadas aos programas de controle e prevenção dos distúrbios nutricionais (Brasil, 2008). Para tanto, a principal estratégia constitui-se em metodologias pedagógicoeducacionais em saúde.

A competência deste profissional para integrar o NASF está, teoricamente, estabelecida em sua formação acadêmica, a qual o instrumentaliza a realizar o diagnóstico nutricional da população, tornando-o, assim, o único profissional a receber uma instrução específica (Assis et al., 2002) que lhe permite propor orientações dietéticas cabíveis e necessárias, adequando-as aos hábitos da unidade familiar, à cultura, às condições fisiológicas dos grupos e à disponibilidade de alimentos. Trata-se, portanto, de um profissional apto a participar ativamente da recriação das práticas saudáveis de alimentação e nutrição e a melhoria da atenção à saúde no Brasil.

A percepção das nutricionistas pesquisadas sobre a importância do próprio trabalho realizado mostra-se condizente, ao menos em teoria, com o que ditam os documentos oficiais do Ministério da Saúde, não somente enquanto profissionais da área da Nutrição, mas também como integrantes de uma equipe se Saúde da Família.

Segundo 66,67\% da amostra, são realizadas ações de EAN pelo NASF para promover a saúde da população, principalmente através de exposições orais (palestras e aconselhamento dietético). A escolha dos temas a serem abordados nessas ações decorre em função da demanda da população através do atendimento ambulatorial (50\% das respostas), da demanda de outros profissionais de saúde (30\% das respostas) ou em decorrência de surto de casos específicos (10\% das respostas), conforme exposto no trecho do DSC 2 abaixo. Os 10\% restantes das respostas obtidas não responderam ao propósito da pergunta (em branco).

As ações de educação, apesar de incipientes, são realizadas por faixa etária/ciclo da vida em grupos formados para orientação sobre alimentação saudável. Existe demanda da própria comunidade, através de problemas que surgem nas consultas ambulatoriais, pelos demais profissionais da equipe ou quando é identificado algum ponto crítico. 
O conceito de educação em saúde está ancorado no conceito de promoção da saúde, que trata de processos que abrangem a participação de toda a população no contexto de sua vida cotidiana e não apenas das pessoas sob risco de adoecer (Machado et al., 2007). Conforme Alves (2005), a educação em saúde constitui um “conjunto de saberes e práticas orientados para a prevenção de doenças e promoção de saúde” que exigem continuidade e permanência.

As ações educativas, no contexto da ESF, devem emergir como instrumento essencial para incentivar a auto-estima e o autocuidado dos membros das famílias, promovendo reflexões que conduzam a modificações nas atitudes e comportamentos (Machado et al., 2007), a partir da adoção de estratégias que permitam o diálogo e a troca entre o popular e o empírico. O conceito de autocuidado, enfatizado nos últimos anos, proporciona ao indivíduo comprometido com o processo educativo preparação e capacitação, conscientemente, para atuar com responsabilidade em seus atos relacionados à alimentação (Boog, 1996).

Entretanto, várias pesquisas têm demonstrado que na prática verifica-se a predominância de paradigmas de educação em saúde que reforçam práticas reducionistas, requerendo questionamentos para o alcance de ações integradas e participativas (Machado et al., 2007).

Analisando-se os dados obtidos por este trabalho em seu contexto geral, pode-se inferir que as ações de EAN executadas pelas nutricionistas do NASF não são aquelas pregadas pelo conceito de Educação em Saúde acima exposto. Esse resultado corrobora com o que diz Sales (2009), segundo o qual as práticas de educação em saúde hegemônicas nos serviços de saúde hoje ainda são acríticas, fragmentadas, centradas na doença, fragilizadoras da participação social. Quer dizer, não conseguem promover as rupturas necessárias para a transformação social desejada.

A perspectiva educacional em Nutrição não deve se limitar a subsidiar os indivíduos com informações. O papel de educador do nutricionista seria o de informar e estimular reflexões críticas sobre a realidade social vivida e enfrentada pelos indivíduos, e identificar os obstáculos que limitam o acesso à qualidade de vida e ao pleno exercício dos direitos de cidadão, para encontrar, individual e coletivamente, caminhos para superar essas condições (Franco e Boog, 2007). Isso não significa impor certa visão de mundo, mas dialogar com o educando de forma que o processo ensino-aprendizagem aconteça a partir do conhecimento crítico da realidade (Freire, 1985), levando-o, 
enquanto sujeito histórico de transformação, a ter consciência e subsídios para uma mudança social efetiva.

As ações de educação alimentar e nutricional identificadas por este trabalho são implantadas a partir de quatro estratégias principais: palestras em grupos específicos segundo patologia ou fase da vida, trabalho realizado em conjunto com equipe multidisciplinar, nas consultas ambulatoriais individualizadas e nas visitas domiciliares (gráfico 2). Essas ações ficam evidenciadas pelo DSC 3 obtido baixo:

Há processo de planejamento de atividades e palestras voltadas para hipertensos, diabéticos, mães de crianças, gestante, idosos, mulheres com excesso de peso em grupos específicos ou nas consultas ambulatoriais. Há participação de terapeuta ocupacional, médicos, enfermeiros, nutricionista, odontóloga, auxiliares de enfermagem, equipes do Programa de Saúde da Família, agentes comunitários de saúde (ACS). Realizo visitas domiciliares quando os ACS me solicitam ajuda a algum paciente acamado ou quando a família precisa de um acompanhamento mais próximo.

Segundo a Matriz de Ações de Alimentação e Nutrição na Atenção Básica (Brasil, 2009a) o nutricionista deve realizar ações educativas, universais ou específicas, prioritariamente como forma de prevenir doenças e promover saúde, segundo nível individual, familiar ou coletivo de intervenção. Porém, a educação nutricional aqui pretendida exige não apenas um conteúdo revolucionário, mas um processo de discussão revolucionário que consiga romper com a transmissão vertical (Vasconcelos, 2004).

A literatura aponta que as estratégias pedagógicas utilizadas pelos profissionais de saúde nos respectivos serviços com maior freqüência são: palestras, cartazes e folhetos (Lima et al., 2000). Percebe-se também a existência de vários recursos audiovisuais para aplicação das ações de educação em saúde, apesar desta diversidade não estar presente na maioria dos serviços.

Nos NASFs pesquisados, a estratégia mais utilizada é a exposição oral (palestras e aconselhamentos dietéticos), em conjunto com a equipe multiprofissional (66,66\%), durante visitas domiciliares, reunião de grupos específicos ou consultas ambulatoriais. Apesar da maior parte da demanda vir de um diagnóstico baseado na experiência diária de atendimento à população, a abordagem específica sobre o problema em questão não é consensuada entre população e nutricionista. 
A título de exemplo, depreende-se do DSC 3 que houve formação de grupo de diabéticos devido à grande procura dos serviços oferecidos nas unidades básicas de saúde. Porém, uma vez identificados esses usuários diabéticos, eles são reunidos para palestras cujos assuntos são definidos isoladamente pela nutricionista ou pela equipe de profissionais. Enquanto estes profissionais insistem em palestrar sobre aspectos técnicos e teóricos sobre diabetes (carboidratos, insulina, alimentação), é possível que os pacientes diabéticos estejam desejosos de atividades educacionais mais pragmáticas, como por exemplo, como fazer doces com edulcorantes em substituição à sacarose.

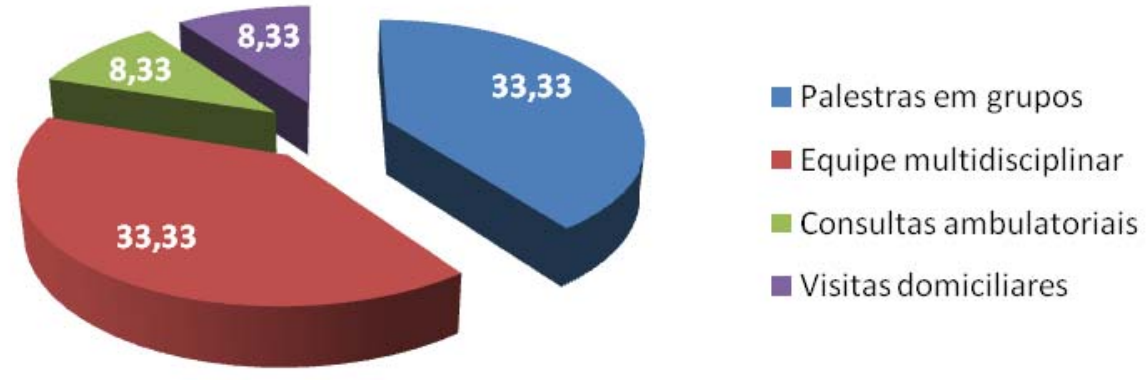

Gráfico 2. Estratégias de educação alimentar e nutricional utilizadas pelos nutricionistas do NASF do DF. Fevereiro de 2010.

A eficácia desse tipo de intervenção está diretamente ligada a fatores que interferem no interesse da população ao que está sendo proposto na atividade educacional. Logo, nível de linguagem, tipo de informação, tipo de metodologia escolhidos para atrair a atenção e estimular o diálogo entre profissional e usuários são quesitos fundamentais para o sucesso de uma intervenção educacional. Segundo Jaime et al.(2007), quando essa ação combina informação e motivação, acaba sendo muito bem sucedida em ambientes, principalmente os mais pobres.

Esse pensamento é corroborado por Ferreira (1986), ao afirmar que 83\% do que aprendemos decorre da visão, $11 \%$ da audição e 3,5\% do olfato. Além disso, ainda segundo este autor, retemos $30 \%$ da informação que vemos, $50 \%$ quando vemos e ouvimos, e 90\% quando dizemos e praticamos. Esses dados indicam que quanto mais recursos pedagógicos forem incorporados à prática rotineira da palestra, mais resultados serão alcançados.

Vale ressaltar ainda que uma correta avaliação da ação educacional executada pode garantir que eventuais falhas no processo de planejamento e execução sejam 
corrigidas e, possam, posteriormente, atingir o público final da forma como se pretende pela educação em saúde.

Atualmente, tem havido uma priorização em desenvolver novas teorias e métodos educativos em nutrição que sejam transformadores, com foco na mudança dos hábitos alimentares. Entre eles, destaca-se o resgate da culinária como uma prática educativa que valoriza a cultura da comunidade e a participação ativa dos indivíduos envolvidos, sendo um instrumento viável para a promoção das práticas da alimentação Saudável (Rodrigues \& Roncada, 2008).

Conforme legislação em vigor (Brasil, 2008) está previsto que os NASFs atuarão em parceria com as equipes da saúde da família em inúmeras atividades interdisciplinares, entre elas educação permanente em saúde e promoção de ações multiprofissionais de reabilitação (Malta et al., 2009); e apoio às equipes da saúde da família na abordagem e atenção adequadas aos agravos severos ou persistentes na saúde de crianças e mulheres.

Apesar de o trabalho realizado em equipe multidisciplinar ser uma estratégia mencionada e utilizada pelas nutricionistas do NASF do DF, elas também colocaram que existe um despreparo muito grande dos profissionais que compõem as equipes para a efetivação desse tipo de trabalho: integrado e interdisciplinar.

O que se busca é a superação da fragmentação do conhecimento, reconhecendo e respeitando as especificidades de cada área profissional em todos os níveis de atenção em saúde (Loch-Neckel et al., 2009). Contudo, Boog (2008) argumenta em seu trabalho que não há na literatura referência realmente positiva da experiência de trabalho em equipe, apesar de ele, em princípio, fazer parte do cotidiano da maioria dos profissionais que trabalham em saúde pública.

O despreparo da equipe multiprofissional para trabalhar em equipe integrada engloba mais do que a vontade de partilhar práticas e saberes. Envolve a formação acadêmica dos profissionais, ainda moldada, segundo Ferreira \& Magalhães (2007), sob a vertente biológica da atenção clínico-assistencial estruturada no modelo biomédico dominante.

Conseqüentemente, esse fato gera entraves na implementação de medidas de intervenção mais consistentes e com vistas à integralidade. E essa tem sido uma tendência de todas as profissões da área da saúde, e não somente do nutricionista. Contudo, isso apenas sinaliza que é preciso superar as práticas convencionais e 
fragmentadas, oriundas do atual modelo de formação acadêmica (Boog, 2008; Ferreira \& Magalhães, 2007).

Uma outra estratégia de EAN citada na pesquisa é o atendimento ambulatorial. Essa modalidade de atendimento remete a um conhecimento teórico sobre aconselhamento dietético (Franco \& Boog, 2007) que por definição tem um caráter reducionista sobre o que propõe a educação em saúde. O aconselhamento dietético geralmente ocorre de forma desarticulada, vertical e pontual, ou seja, é mera informação.

É claro que essa estratégia tem importância indiscutível consoante a finalidade a que se propõe fazê-la, mas considerá-la como ferramenta de educação alimentar nutricional, de caráter reflexivo, crítico e contínuo é uma suposição totalmente errônea. Novamente, entende-se a integralidade no cuidado de pessoas, grupos e coletividade, sob a óptica educacional, percebendo-os como sujeito histórico, social e político, articulado ao seu contexto familiar, ao meio ambiente e à sociedade na qual se inserem (Machado et al., 2007) demandando, para tanto, continuidade de tais ações.

Segundo 83,33\% dos profissionais pesquisados, não são feitas parcerias para realizar as ações de educação alimentar e nutricional. A partir de suas falas (Não, só os próprios recursos do centro de saúde.) é possível inferir que não há envolvimento com organizações não-governamentais, igrejas, escolas, segmentos do próprio governo e outras entidades da sociedade civil para promover a alimentação saudável da população em questão.

Em seus quase vinte anos de existência, a ESF continua sendo vista como modelo inovador, fundamentado em uma ética social e cultural, concretizando o ideário de promoção da saúde, na perspectiva da qualidade de vida do povo brasileiro. Entretanto, sua sustentabilidade requer o estabelecimento contínuo de parcerias intersetoriais, articulando ações interdisciplinares de assistência, prevenção e promoção da saúde (Machado et al., 2007). E isso certamente inclui os NASFs.

Vários estudos, como o de Sawaya (2006), ressaltam a importância de relações e parcerias institucionais dentro e fora do setor saúde para promover a alimentação adequada. Considerando o processo de educação alimentar e nutricional, é possível: aliar o cultivo de hortas e 'merenda' em ambiente escolar; aliar Pastoral da Criança e Secretaria Municipal de Abastecimento a oficinas de reaproveitamento de alimentos; 
aliar hortas comunitárias e correto manejo dos alimentos ali produzidos; aliar lideranças comunitárias e aparelhos sociais; entre outros.

É como se no Distrito Federal as nutricionistas ainda estejam dispersas ao fato de que a construção de identidade do NASF perpassa necessariamente por aquilo que elas pensam e fazem e se faz presente de forma contínua no trabalho diário. Transpassa para essa pesquisadora a idéia de que elas só podem lutar por um NASF condizente à política que o instituiu a partir do momento em que a equipe mínima estiver completa e quando houver um gestor próprio para o NASF. Esta atitude passiva não corrobora com o nível formação acadêmica humanista e crítica preconizada pela resolução nº5/2001 do Conselho Nacional de Educação (Brasil, 2001).

O não estabelecimento dessas alianças cooperativas no DF pode estar intimamente relacionado com o fato da equipe multiprofissional não trabalhar de fato como equipe, e sim como um agrupamento de profissionais; ou em decorrência da desorganização política do gestor em saúde ao promover a implantação de uma política e não reservar para isso um responsável competente e comprometido com a causa da atenção básica como um todo.

Somente através de articulações institucionais é possível a união de 'vontades' rumo à causa da alimentação saudável, potencializando o resultado expresso em termos de melhoria de saúde da população, evitando-se a superposição de iniciativas e o desperdício de recursos, principalmente financeiros e humanos. Por outro lado, sabe-se que a mudança das práticas educativas em nutrição demanda tempo, vontade e dinheiro e, exatamente por isso deve ocorrer de forma articulada a outros setores do governo e da sociedade civil organizada (Brasil, 2007).

\section{Condições de trabalho no NASF para realização de EAN}

Quando indagadas sobre as condições de trabalho de que dispunham no NASF para realização das ações de EAN - seja em termos de remuneração, estrutura física, apoio gerencial, recursos materiais, capacitação e atualização profissional, ou outro -, 83,33\% da amostra consideraram-nas satisfatórias (boas ou entre regular e boas), contrapondo as $16,67 \%$ que as consideraram ruins ou regulares. 
Muito embora as condições de trabalho sejam satisfatórias em algum grau para a maioria das nutricionistas, 21,43\% alegaram que a estrutura física é inadequada para realização da atenção nutricional junto à população, com concomitante ocorrência de desvio de função do cargo de trabalho cotidiano, além de despreparo da equipe multidisciplinar ao trabalhar em conjunto. Por outro lado, a satisfação alegada baseia-se no fato de que há apoio e incentivo gerencial para a realização do trabalho e para implementação de novas idéias (tabela 1). No trecho abaixo (DSC 4), é possível constatar esse resultado.

Tabela 1. Aspectos que afetam a satisfação das nutricionistas do NASF em relação às condições de trabalho. Brasília, fevereiro de 2010.

\begin{tabular}{c|c|c|c}
\hline Aspectos positivos & $\mathbf{\%}$ & Aspectos negativos & $\%$ \\
\hline Apoio e incentivo gerencial & \multirow{2}{*}{$\mathbf{1 4 , 2 9}$} & Falta de apoio e incentivo gerencial & 7,14 \\
\cline { 3 - 4 } & & Desvio de função & $\mathbf{2 1 , 4 3}$ \\
\hline Estrutura física adequada & 14,29 & Estrutura física inadequada & $\mathbf{2 1 , 4 3}$ \\
\hline Boa relação com a equipe & 7,14 & Despreparo da equipe multidisciplinar & $\mathbf{1 4 , 2 9}$ \\
\hline
\end{tabular}

A estrutura física é razoável, mas não existe um espaço físico definido para o NASF. Não existe um coordenador do NASF e nunca houve uma reunião para organização do trabalho. A equipe está incompleta e fica difícil a interação e a criação de identidade do NASF, já que há concorrência e pouco preparo dos profissionais para trabalhos multiprofissionais. Não há muita abertura e interação entre os colegas de trabalho. Assim, há dificuldade de trabalhar: assistência direta ao usuário e atendimento ambulatorial. Por outro lado, a chefia direta incentiva e dá autonomia de atuação e para desenvolver os projetos prioritários, e os profissionais reconhecem a importância e respeitam o meu trabalho.

Segundo dados obtidos no estudo de Santos (2005) sobre a percepção dos profissionais das equipes da ESF sobre o nutricionista, a maioria dos trabalhadores de 
saúde que compuseram a amostra desconheciam a real função do nutricionista e suas atribuições, associando o conceito deste profissional à mera prescrição de dietas. Tal fato estaria gerando, por conseguinte, a desvalorização dessa categorial profissional (Boog, 1999; Santos, 2005).

Infere-se, assim, que tal posicionamento (desvalorização e desconhecimento da função) acaba sendo assumido também pelo gestor da atenção básica do DF, uma vez que, conforme identificado neste trabalho, as nutricionistas têm sido desviadas de sua função enquanto profissionais do NASF por falta de motivação, incentivo e até mesmo de um coordenador capaz de criar uma identidade própria e delimitar um campo de atuação inerente ao NASF. Quer dizer, muito embora o NASF traga em seu bojo uma nova lógica de intervenção na ESF, claramente expresso em sua portaria de criação (Brasil, 2008), o gestor do DF insiste em confiná-las ao trabalho ambulatorial, fragmentado e individualizado, desrespeitando o princípio da integralidade.

O despreparo da equipe multiprofissional para trabalhar em equipe integrada, já mencionado e discutido em seção anterior, é um problema recorrente segundo as nutricionistas pesquisadas, e indica que o gestor responsável pela atenção básica deve atentar-se para a equalização desse obstáculo no planejamento e execução de ações de EAN mais efetivas e condizentes com a proposta da educação em saúde.

Ao questioná-las sobre motivação, 71,43\% das respostas obtidas revelaram não haver qualquer tipo de motivação por parte do gestor ou da chefia imediata na unidade básica de saúde. Esse resultado é coerente com o que foi obtido em pergunta anterior, quando somente 14,29\% das respostas indicaram haver apoio e incentivo gerencial.

Contudo, segundo as demais 28,57\% das respostas dadas pelas nutricionistas, há algum tipo de motivação por parte somente da chefia direta da unidade básica de saúde (não necessariamente um nutricionista), sendo que 37,5\% das respostas indicaram que, conforme DSC 5 abaixo, os meios mais utilizados para motivá-las são: a abertura para o diálogo incentivo e apoio para realização de novos trabalhos e qualificação profissional.

Só a chefia direta motiva a fazer trabalhos diferentes, providencia materiais e recursos humanos necessários, que façamos cursos e é aberta a sugestões.

Ao abrir espaço para o diálogo com os profissionais hierarquicamente inferiores, o gestor estimula a gestão compartilhada das ações propostas, co-responsabilizando toda 
a equipe pela execução delas. Sem mencionar, claro, que as lacunas residuais de comunicação acabam sendo eventualmente superadas, na medida em que ela passa a ser direta - sem mediadores -, mais rápida e desburocratizada.

As estratégias de planejamento e gestão compartilhada, por serem participativas, contribuem para o crescimento do capital humano e do capital social, ampliando as possibilidades de empoderamento dos profissionais da saúde (De Paula, 2005) ao identificar, conjuntamente, potencialidades, oportunidades, problemas, limites e obstáculos à implementação das ações de EAN, por exemplo.

A qualificação profissional identificada pelo estudo como um preditor motivacional pode ser aqui entendida como a proposta política de Educação Permanente em Saúde, que se constitui estratégia fundamental às transformações do trabalho no setor para que venha a ser lugar de atuação crítica, reflexiva, propositiva, compromissada e tecnicamente competente (Ceccim, 2005).

A educação no contexto da ESF configura-se, então, não somente mediante o binômio profissional/usuário, mas também através do gestor/profissional. Através de capacitações e qualificações, os profissionais cada vez mais se apropriam de ferramentas para lidar com as barreiras que lhe são impostas no trabalho cotidiano e para o adequado manejo que o contexto epidemiológico-nutricional atual exige. Quanto maior a freqüência, e quanto mais aprofundadas e contextualizadas forem as questões abordadas junto aos profissionais do NASF, mais este profissional estará apto atuar.

Por fim, como um apanhado geral, 83,33\% alegaram estar satisfeitas, em maior ou menor grau, quando questionadas sobre a satisfação com o trabalho atual realizado (DSC 6): Sim, estou, porque gosto de atuar na atenção primária. Mas deixo de desempenhar várias ações pela exigência da chefia. Me deixam angustiada consultas individualizadas em ambulatório.

Isto torna-se positivo na medida em que, apesar da ciência de que falhas que precisam ser corrigidas, demonstra-se que o nutricionista vê seu trabalho como importante junto à comunidade e que as ações do NASF ainda podem conseguir se ajustar melhor à realidade do DF, atendendo as expectativas não só do profissional mas, principalmente, da comunidade. 


\section{Considerações Finais}

Este estudo leva-nos a refletir que as estratégias e ações de educação alimentar e nutricional realizadas pelos nutricionistas do NASF do Distrito Federal em muito precisam ser melhoradas - seja em termos técnicos, estruturais, operacionais e de articulação - para gerarem resultados efetivos na promoção da alimentação saudável junto à população coberta do DF.

A atuação do nutricionista em grande parte dos municípios brasileiros ainda precisa ser fortalecida (Brasil, 2009a) para que a potencialidade do conhecimento da Nutrição e das intervenções neste campo possam, de forma efetiva, contribuir para a melhoria da qualidade de vida e de saúde da população, em prol da promoção da alimentação saudável.

Está claro que a promoção da alimentação saudável não pode ser uma responsabilidade exclusiva dos nutricionistas, e precisa ser compartilhada não só pelas equipes de saúde, como também por órgãos e entidades que transcendem os serviços de saúde. Porém, o nutricionista deve sempre ser o referencial dentro da equipe quanto a esses aspectos (Boog, 2008).

Faz-se necessário também, conforme orientado por Santos (2005), aprofundar a discussão sobre o papel e metodologias da educação alimentar e nutricional dentro da complexificação do contexto epidemiológico atual, e qual seria a sua real contribuição para as novas demandas apontadas na promoção das práticas alimentares saudáveis.

Na medida em que a educação nutricional, voltada à promoção da alimentação saudável, constitui uma das diretrizes da Política de Alimentação e Nutrição, cabe também analisar as condições em que se dá a formação do nutricionista como educador, sendo que um dos aspectos que consolidam essa formação é a relação entre teoria e prática (Franco \& Boog, 2007).

Além de sua defasada formação acadêmica, o nutricionista do NASF do DF padece de um gestor próprio, competente e firme, capaz de encabeçar a construção de identidade e práticas próprias do NASF, a partir das diversas realidades aqui vivenciadas. Necessitam de um líder legítimo, que compartilhe das decisões, mas que também exija competência, perseverança e alegria na meta educacional a ser atingido.

Recomenda-se, ainda, a realização de estudos capazes de caracterizar que estratégias pedagógico-educacionais são mais eficientes, que comparem o ganho de conhecimento da população antes-depois da ação dos NASFS ou programas similares. 
Apesar de a PNAN afirmar a EAN como instrumento indispensável para promoção da alimentação saudável, ela não determina como isto deve ser feito. E nem deve, já que a prática educacional deve ser moldada conforme a realidade de cada grupo populacional. Contudo, mais experiências precisam ser relatadas para que o conhecimento nesse campo seja cada vez mais aprofundado.

Assim, muito embora o desafio imposto à categoria dos nutricionistas remeta a mudanças estruturais, que têm início na própria formação acadêmica do profissional (Ferreira \& Magalhães, 2007), tal fato por si só não descaracteriza a competência desse profissional para atuar na Atenção Básica ou mesmo nos NASFs. 


\section{Referências Bibliográficas}

1. ALVES, V. S. Um modelo de educação em saúde para o Programa Saúde da Família: pela integralidade da atenção e reorientação do modelo assistencial. Interface Comunic., Saúde, Educ., v.9, n.16, p.39-52, fev.2005.

2. ASSIS, A. M. O., et al. O Programa Saúde da Família: contribuições para uma reflexão sobre a inserção do nutricionista na equipe multidisciplinar. Rev. Nutr., Campinas, 15(3):255-266, set./dez., 2002.

3. BRASIL. Instituto Brasileiro de Geografia e Estatística. Estudo Nacional da Despesa Familiar - ENDEF: dados preliminares - consumo alimentar - antropometria. Rio de Janeiro: IBGE; 1977.

4. _ Conselho Nacional de Educação. Resolução CNE/ CES $\mathbf{n}^{\mathbf{0}} \mathbf{5}$ de 07 de novembro de 2001. Brasília, 2001.

5. — Ministério da Saúde. Secretaria de Atenção à Saúde. Departamento de Atenção Básica. Política Nacional de Alimentação e Nutrição - 2. ed. rev. - Brasília: Ministério da Saúde, 2003.

6. ـ Instituto Brasileiro de Geografia e Estatística. Pesquisa de Orçamentos Familiares - 2002-2003: Antropometria e análise do estado nutricional de crianças e adolescentes no Brasil. Rio de Janeiro; 2004.

7. • Ministério do Planejamento, Orçamento e Gestão. Ministério do Desenvolvimento Social e Combate à Fome. Instituto Brasileiro de Geografia e Estatística. Pesquisa Nacional por Amostra de Domicílios. Suplemento: Segurança Alimentar, 2004. Rio de Janeiro, 2006.

8. _ _ Ministério da saúde. Departamento de Atenção Básica. Estratégias de promoção da alimentação saudável para o nível local. Relatório da oficina Trabalho do I Seminário sobre Política Nacional de Promoção da Saúde. Brasília, 2007.

9. . Ministério da Saúde. PORTARIA No 154 . Cria os Núcleos de Apoio à Saúde da Família - NASF. Brasília, março de 2008.

10. —. Ministério da Saúde. Secretaria de Atenção à Saúde. Departamento de Atenção Básica. Matriz de ações de alimentação e nutrição na Atenção Básica de saúde. Brasília: 2009 (a).

11. _. Ministério da Saúde. Secretaria de Vigilância em Saúde. Secretaria de Gestão Estratégica e Participativa. Vigitel Brasil 2008: vigilância de fatores de risco e proteção para doenças crônicas por inquérito telefônico. Brasília: 2009 (b).

12. BRASÍLIA. Secretaria de Estado de Desenvolvimento Urbano e Habitação. Projeção de população para o Distrito Federal, segundo as regiões administrativas: 20062020. Brasília, 2005. Disponível em: http://www.saude.df.gov.br/dadosestatisticos > Acesso em 18/02/2010. 
13. BOOG, M.C.F. Educação nutricional em serviços públicos de saúde: em busca de espaço para ação efetiva [doutorado]. São Paulo: Faculdade de Saúde Pública, Universidade de São Paulo; 1996.

14. _. Atuação do nutricionista em saúde pública na promoção da alimentação saudável. Revista Ciência \& Saúde, Porto Alegre, v.1, n. 1, p.33-42, jan./jun, 2008.

15. CAMPOS, A. M. O trauma de uma intervenção Federal em Brasília. Correio Braziliense, 17 de fevereiro de 2010. Disponível em: < http://www.correiobraziliense.com.br/app/noticia182/2010/02/17/cidades,i=174067/O+TRAUMA+DE+ UMA+INTERVENCAO+FEDERAL+EM+BRASILIA.shtml > acesso em 18/02/2010.

16. CECCIM, R.B. Educação Permanente em Saúde: descentralização e disseminação de capacidade pedagógica na saúde. Ciências \& Saúde Coletiva, 10(4): 975-986, 2005.

17. COUTINHO, J. G.; GENTIL, P. C.; TORAL, N. A desnutrição e obesidade no Brasil: o enfrentamento com base na agenda única da nutrição. Cad. Saúde Pública, Rio de Janeiro, 24 Sup 2:S332-S340, 2008.

18. DE PAULA, J. Desenvolvimento \& gestão compartilhada. Agência de Educação para o Desenvolvimento. 2005. Disponível em: < http://www.biblioteca.sebrae.com.br/bds/bds.nsf/be76a0d0f1ecbeff832574b0004bc066/3093035ca1cc0d4 c83257640006a272e/\$FILE/NT00042956.pdf > Acesso em 20/02/2010.

19. FERREIRA, O. M. C.; JÚNIOR, P. D.S. Recursos audiovisuais no processo ensino aprendizagem. São Paulo: EPU, 1986.

20. FERREIRA, V.A.; MAGALHÃES, R. Nutrição e promoção da saúde: perspectivas Atuais. Cad. Saúde Pública, Rio de Janeiro, 23(7):1674-1681, jul, 2007.

21. FRANCO, A.N.; BOOG, M.C.F. Relação teoria-prática no ensino de educação nutricional. Rev. Nutr., Campinas, 20(6):643-655, nov./dez., 2007.

22. FREIRE, Paulo. Pedagogia do oprimido. Rio de Janeiro, Paz e Terra, 1983.

23. __ E Educação e mudança. 10a. ed. Rio de Janeiro: Paz e Terra; 1985.

24. JAIME, P.C.. et al. Educação nutricional e consumo de frutas e hortaliças: ensaio Comunitário controlado. Rev Saúde Pública, 2007.

25. JODELET, D. Representações sociais : um domínio em expansão. In: As Representações sociais. Rio de Janeiro: Eduerj, 2002.

26. LEFEVRE, F.; LEFEVRE, A.M. O discurso do sujeito coletivo: um novo enfoque em pesquisa qualitativa. Caxias do Sul: Educs, 2003.

27. . O sujeito coletivo que fala. Interface - Comunic, Saúde, Educ, v.10, n.20, p.517-24, jul/dez 2006.

28. LIMA, R.T., et al. Educação em saúde e nutrição em João Pessoa, Paraíba. Rev. Nutr., Campinas, 13(1): 29- 36, jan./abr., 2000. 
29. LOCH-NECKEL, G., et al. Desafios para a ação interdisciplinar na atenção básica: implicações relativas à composição das equipes de saúde da família. Ciência \& Saúde Coletiva, 14 (Supl. 1):1463-1472, 2009.

30. MACHADO, M.F.A.S., et al. Integralidade, formação de saúde, educação em saúde. Ciência \& Saúde Coletiva, 12(2):335-342, 2007.

31. MALTA, D. C., et al. A Política Nacional de Promoção da Saúde e a agenda da atividade física no contexto do SUS. Epidemiol. Serv. Saúde, Brasília, 18(1):79-86, jan-mar 2009.

32. RODRIGUES, L.P.F.; RONCADA, M.J. Educação nutricional no Brasil: evolução e descrição de proposta metodológica para escolas. Com. Ciências Saúde. 19(4):315322. 2008.

33. SÁ, C. P. Construção do objeto de pesquisa em representações sociais. Rio de Janeiro: EDUERJ, 1998.

34. SALES, C. M. Possibilidades e limites de execução das ações de promoção da saúde nos moldes da educação popular em saúde na Estratégia de Saúde da Família. Tese de doutorado. Programa Multiinstitucional em Ciência da Saúde - Rede Centro-Oeste: UnB, UFG e UFMS. Campo Grande, 2009.

35. SANTOS, L.A.S. Educação alimentar e nutricional no contexto da promoção de práticas alimentares saudáveis. Rev. Nutr., Campinas, 18(5):681-692, set./out., 2005.

36. SAWAYA, A.L.; Comida e Educação. Estudos Avançados, 20 (58), 2006

37. SENNA, M. C. M. Eqüidade e política de saúde: algumas reflexões sobre o Programa Saúde da Família. Cad. Saúde Pública, Rio de Janeiro, 18(Suplemento):203-211, 2002.

38. UNIVERSIDADE DE BRASÍLIA. Biblioteca Central. Normas bibliográficas segundo ABNT. Disponível em < http://www.bce.unb.br/index.php?option=com_content\&view=article\&id=53\&Itemid=4 $\underline{3}>$ Acesso em 26/03/2010.

39. VASCONCELOS, E. M. Educação Popular: de uma prática alternativa a uma estratégia de gestão participativa das políticas de saúde. PHYSIS: Rev. Saúde Coletiva. 2004;14(1): 67-83. 